\title{
Estimated date of discharge for surgical admission: a way forward
}

This article was published in the following Dove Press journal:

Clinical Audit

5 September 2017

Number of times this article has been viewed

\section{Anil Bagul \\ Duff M Bruce}

Department of General Surgery, Aberdeen Royal Infirmary, Foresterhill, Aberdeen, UK
Correspondence: Duff M Bruce UGI and Bariatric Unit, Department of General Surgery, Aberdeen Royal Infirmary, Foresterhill, Aberdeen, AB 25 2ZD, United Kingdom Tel +44 ol 22455 I 275 Fax +44 0I 224443212 Email duff.bruce@nhs.net
Introduction: The Planned Care Improvement Programme has highlighted the importance of developing a robust framework that supports the implementation of good clinical practice in the National Health Service. An important aspect of this process is the efficient management of patient discharge. Early prediction of an estimated date of discharge (EDD) may enable a structured discharge process.

Aims: To examine how accurately clinical staff predict a date of discharge and to identify factors that may result in discrepancies between predicted and actual date.

Design: Data was collected prospectively for all admissions to a general surgical ward at the Aberdeen Royal Infirmary. Patients were allocated an EDD upon admission by the most senior medical staff on the post-admission ward round.

Assessment and analysis: Surgical wards were piloted as areas supported by operational support to achieve EDD for all patients. Wards visited showed variable results.

Results: Forty-six (44.2\%) medical staff correctly predicted the discharge date. Eighteen $(11.4 \%)$ patients were discharged prior and 64 (40.5\%) after their EDDs; of these 64, 12 (21.8\%) had multiple factors causing the delay. Measurement of improvement was assessed by the number of patients with an accurate EDD and reasons causing a delay to discharge.

Conclusion: Extra unit referrals projected most delays, indicating a need for changes in the referrals system. This study highlights some of the causes for discrepancies and areas where system changes may influence the length of hospital stay. EDD has a positive impact on length of hospital stay.

Keywords: date of discharge, hospital stay, planned care improvement, planned discharge

\section{Introduction}

The Planned Care Improvement Programme is a key element in Scotland's Health Planned Care Work stream, and is a national-level action. All health boards are expected to participate in the program. In implementing delivering for health, boards have been tasked with achieving a shift in the balance of care. Boards should have projects planned to rebalance their portfolios of services and ensure that improvements are made in productivity and capacity, while sustaining improvements in waiting times and reducing the need for hospital admissions.

The program will draw upon the growing body of Clinical Systems Improvement science from around the world and provide a framework to allow the application of these evidence-based changes and best practice to create local solutions for local problems. The focus of the program was directed to shifting the balance of care, diagnostics methodology, child and mental health, rural health care services, unscheduled care, 
mental health services, tackling health inequalities along with long term conditions, and implementation of technology and training towards health.

The Kerr report ${ }^{1}$ identified five simple changes integral for delivering improvements in the above mentioned areas. The health boards were directed to draw up 3-year improvement plans for introducing and implementing changes leading to Improvement in referral and diagnostic pathways as well as treatment of day surgery (rather than inpatient surgery) as the norm. Admission, discharge, and length of stay in the hospital along with a planned follow-up on discharge should be actively managed. Implementation of these improvements will enable the National Health Service (NHS) in Scotland to make further progress in the delivery of efficient patient-focused services by improving access, flow, and safety along planned care journeys, enabling more care to be delivered locally, and ensuring that patient pathways are planned in advance and that patients have a seamless experience, during which they are informed about their program of care. . $^{2,3}$

The vision of the program is to improve the flow of patients along their health care journeys by ensuring their experience of assessment, diagnosis, and treatment is based on augmented, safe, and reliable clinical systems.

The Planned Care Improvement Programme suggests that improvement in performance could be attained by seeking to attain the following goals: $:^{4,5}$

1. Highlighting the importance of developing a robust framework that supports the implementation of a good clinical practice in the NHS.

2. Improvement and redesign of key processes along the patient journey through the health care system.

3. Efficient management of patient discharge.

4. Early EDD that may enable a structured discharge process to decrease length of hospital stay.

5. Early prediction of discharge date has a positive impact on length of hospital stay.

This study aimed to document the accuracy of predicting EDD by clinical staff in a general surgical unit and identify factors that may influence the accuracy.

\section{Methods}

\section{Patients and setting}

The study was undertaken in a university hospital in the north of Scotland. A consecutive series of 165 patients admitted to two surgical wards over a 4-week period were enrolled prospectively into the study. Patients were allocated an EDD upon admission to the surgical ward by the most senior medical staff leading the patient's initial care on the post-admission ward round.

The study was registered with the Audit Department, at Services Research Unit, Foresterhill - as per Grampian NHS research guidelines, and they approved the study. All patients provided written, informed consent to participate in the study.

\section{Data collection}

A total of 165 data collection forms were collected prospectively. Seven (4.2\%) data collection forms had incomplete data on estimated date of discharge or actual date of discharge and were excluded. The power of study was calculated with aid from the Statistics and Audit Department of the Clinical Excellence Department Grampian NHS trust.

\section{Data analysis}

Data collection forms for this study were approved by the audit committee and the Grampian hospital ethics committee. A total of 158 data collection forms were processed using SNAPTM optical recognition software (SecuGen Corporation, Santa Clara, CA, USA) and analyzed by clinical effectiveness staff using SPSS ${ }^{\text {TM }}$ software (IBM Corporation, Armonk, NY).

\section{Results}

This patient cohort included 158 patients, of which $85(53.8 \%)$ were male and $73(46.2 \%)$ were female. The mean age was 56 (SD range 14-92) (Figure 1). The median length of hospital stay was 6 days (0-53) (Table 1). Emergency admissions accounted for a total of 104 cases, with the dates of discharge correctly predicted for 46 (44.2\%). Of the 54 patients who were admitted for routine procedures, $30(55.5 \%)$ had their date of discharge correctly predicted. EDDs are illustrated in Table 2.

\section{Correctly predicted EDD}

In total, 76 (48.1\%) patients had a correctly predicted EDD. Of these patients, $46(60.5 \%)$ were emergency admissions and the other 30 (39.5\%) were routine admissions. All had a discharge plan upon discharge.

\section{Discharge prior to EDD}

Eighteen (11.4\%) patients were discharged before their EDD. Of these 18 patients, 17 (94.4\%) were admitted as emergency cases and $1(5.6 \%)$ was admitted as a routine case. Fifteen 


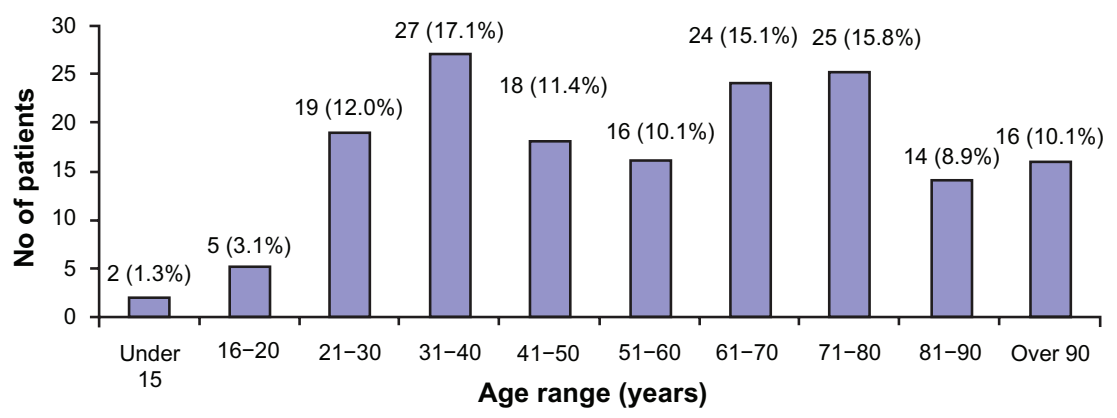

Figure I Cohort age range.

(83.3\%) patients were each given one reason for early discharge (Figure 2). Of the 18 patients discharged before their EDD, $10(55.6 \%)$ had from one to three referrals made. All referrals were completed on the day of request. The reasons for referrals are shown in Figure 3.

\section{Discharge after EDD}

Of 158 patients, 64 (40.5\%) were discharged after EDD. Of the 158 patients, $41(64.1 \%)$ were admitted as emergencies, and $23(35.9 \%)$ were admitted as routine cases. The multiple reasons for exceeding EDD are shown in Figure 4. Of the 64 patients discharged after EDD, $44(69 \%)$ had a discharge plan. Discharge plans are shown in Figures 5 and 6.

Table I Inpatient stay for the cohort group

\begin{tabular}{|c|c|}
\hline Hospital stay duration & Patients, $\mathbf{n}$ \\
\hline$<24$ hours & 18 (1I.4\%) \\
\hline I day & $45(28.5 \%)$ \\
\hline 2 days & 34 (21.5\%) \\
\hline 3 days & 14 (8.9\%) \\
\hline 4 days & $10(6.3 \%)$ \\
\hline 5 days & $4(2.6 \%)$ \\
\hline 6 days & $4(2.6 \%)$ \\
\hline 7 days & $4(2.6 \%)$ \\
\hline 8 days & $\mathrm{I}(0.6 \%)$ \\
\hline 9 days & $5(3.2 \%)$ \\
\hline 10 days & $2(1.3 \%)$ \\
\hline II days & $\mathrm{I}(0.6 \%)$ \\
\hline 12 days & $2(1.3 \%)$ \\
\hline 13 days & $2(1.3 \%)$ \\
\hline 14 days & $2(1.3 \%)$ \\
\hline 15 days & I (0.6\%) \\
\hline 17 days & I (0.6\%) \\
\hline 26 days & $\mathrm{I}(0.6 \%)$ \\
\hline 29 days & $\mathrm{I}(0.6 \%)$ \\
\hline 32 days & I (0.6\%) \\
\hline 35 days & $\mathrm{I}(0.6 \%)$ \\
\hline 41 days & $\mathrm{I}(0.6 \%)$ \\
\hline 47 days & $\mathrm{I}(0.6 \%)$ \\
\hline 48 days & I $(0.6 \%)$ \\
\hline 53 days & I (0.6\%) \\
\hline
\end{tabular}

\section{Discussion}

\section{Brief outline of the problem}

It is apparent that a number of inpatient hospital beds remained occupied by patients undergoing prolonged discharge planning. Early discharge planning may positively influence this process. This requires early EDD; however, there is little evidence to identify whether this can be undertaken accurately. The Planned Care Improvement Programme has highlighted the importance of developing a robust framework that supports the implementation of good clinical practice in the NHS. This should include improvement and redesign of key processes along the patient journey through the health care system. An important aspect of that process is efficient management of patient discharge. It has been suggested that early EDD may enable a structured discharge process to decrease the length of hospital stay.

Table 2 Estimated discharge dates

\begin{tabular}{ll}
\hline Discharge & Patients, $\mathbf{n}$ \\
\hline-7 days & $\mathrm{I}(0.63 \%)$ \\
-4 days & $\mathrm{I}(0.63 \%)$ \\
-3 days & $\mathrm{I}(0.63 \%)$ \\
-2 days & $2(\mathrm{I} .3 \%)$ \\
$-I$ day & $\mathrm{I} 3(8.2 \%)$ \\
Same day & $76(48.1 \%)$ \\
$+\mathrm{I}$ days & $30(19.0 \%)$ \\
+2 days & $\mathrm{I}(7.6 \%)$ \\
+3 days & $7(4.4 \%)$ \\
+4 days & $\mathrm{I}(0.63 \%)$ \\
+5 days & $4(2.5 \%)$ \\
+7 days & $2(\mathrm{I} .3 \%)$ \\
+9 days & $\mathrm{I}(0.63 \%)$ \\
$+I 5$ days & $\mathrm{I}(0.63 \%)$ \\
+23 days & $\mathrm{I}(0.63 \%)$ \\
+24 days & $\mathrm{I}(0.63 \%)$ \\
+26 days & $\mathrm{I}(0.63 \%)$ \\
+35 days & $\mathrm{I}(0.63 \%)$ \\
\hline
\end{tabular}




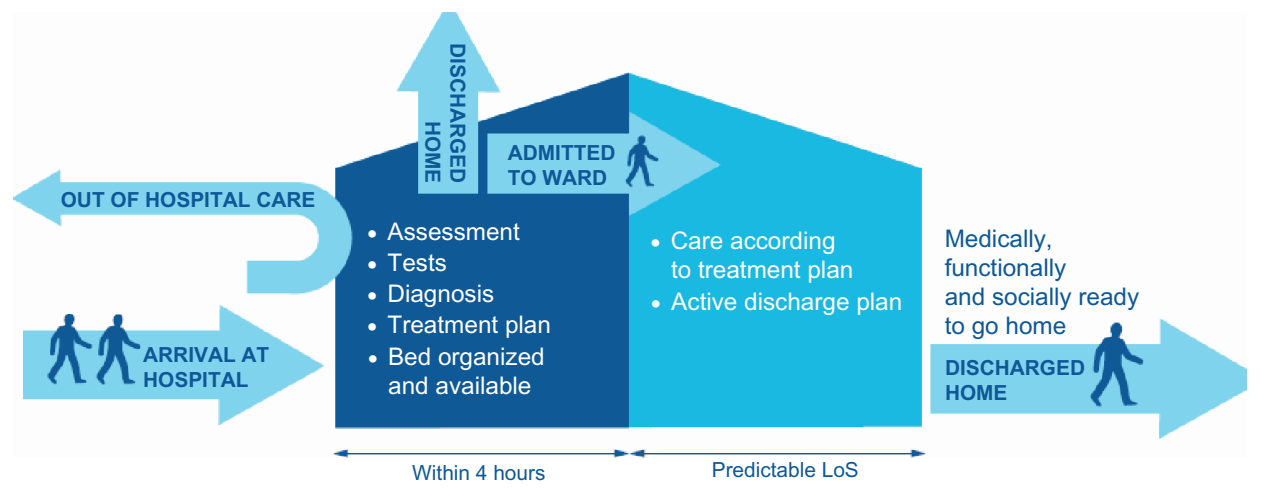

Figure 2 Planned Care Improvement Programme.

Note: Reproduced with permission from the Planned Care Improvement Programme, Scottish Executive, Edinburgh 2006. Available from: http://www.scotland.gov.uk/ Resource/Doc/|4976//0039877.pdf. Copyright permission from Scottish Government Health Directorate.

Abbreviation: LoS, length of stay.

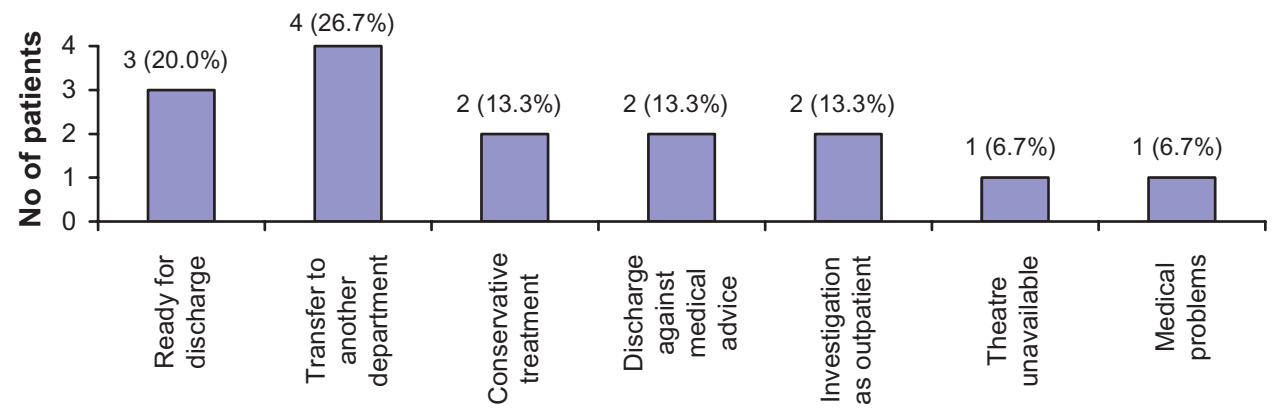

Reason for early discharge

Figure 3 Reasons for discharge earlier than estimated.

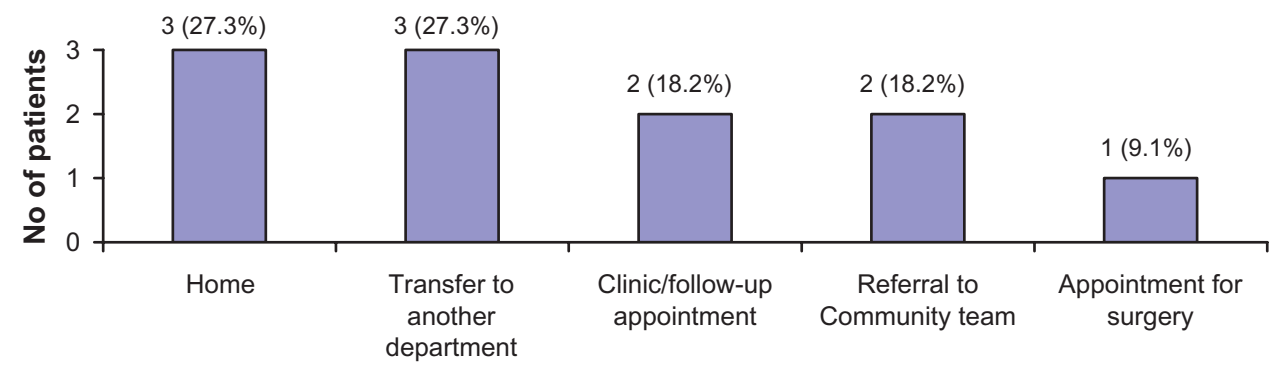

Discharge plan

Figure 4 Reasons for referral in group with discharges later than estimated.

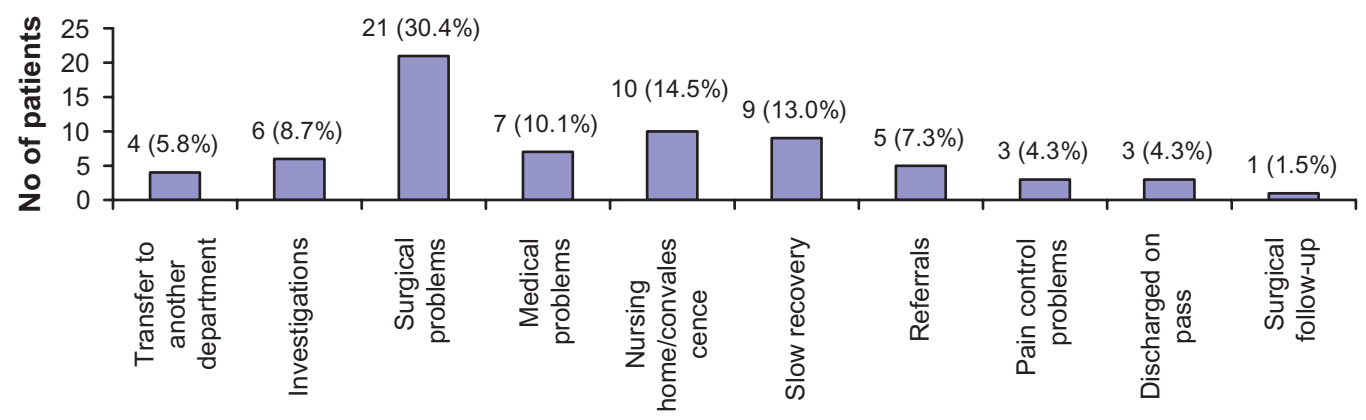

Reasons for late discharge

Figure 5 Reasons for delays in discharge. 


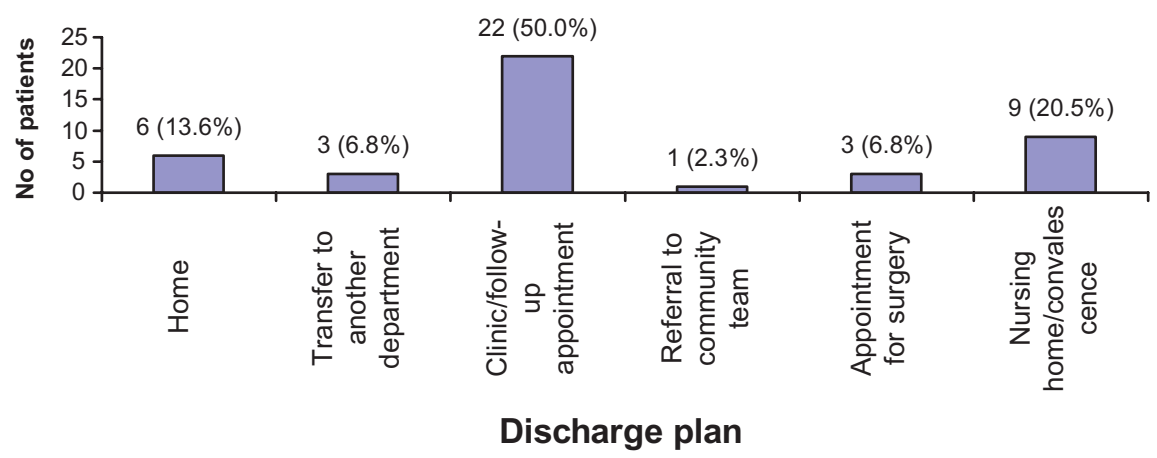

Figure 6 Discharge plans.

\section{Assessment of the problem and cause analysis}

The wards were visited to establish a baseline recording of each currently admitted patient's EDD status. It was discovered that some ward areas attempted to record EDDs in some form, but this varied considerably. Some nurses felt that their wards faired well in forward planning with their discharge process while other wards waited for the doctor on the ward round to make the decision. A discharge process protocol was introduced on the surgical wards, which were then piloted as areas supported by operational support to achieve EDD for all patients.

\section{Strategy for change}

A sustainability of change model identifies the two most important areas in an organization by which to achieve and sustain a change, ie, staff attitude and staff behaviors. As a result, information sessions about EDD and its benefits were organized. It was explained that the initiative from the ward team was compulsory and that their managers would be responsible for enforcing these guidelines, while the operational employees would provide support to achieve it.

\section{Measurement of improvement}

Improvement was assessed based on:

1. The number of patients with an EDD.

2. The number of patients with an accurate EDD.

3. The number of patients who achieved their EDD.

4. The reasons for delays in discharge.

5. The differences in patient journeys between elective and emergency admissions.

Changes in the process would lead to the making of a discharge checklist to highlight issues to be dealt with at least 24 hours prior to discharge, which would be checked on day of discharge.
Patients who were discharged after their EDDs had extra unit referrals made. Approximately $50 \%$ of these did not respond on the same day. Changes in the system for dealing with such referrals may decrease delays and may reflect a decreased time in hospital.

This study suggests that early prediction of discharge dates has a positive impact on length of hospital stay and can play a pivotal role in improving health care.

\section{Conclusion}

The study revealed an accurate EDD in 46 (44.2\%) of patients. Of the 54 patients who were admitted as routine cases, $30(55.5 \%)$ had their date of discharge correctly predicted. Eighteen (11.4\%) patients were discharged prior to their EDDs; 17 of these (94.4\%) were emergencies, and most were managed on the ward for 24 to 48 hours, which strengthens an argument for an emergency care center unit with a facility to discharge early. Sixty-four (40.5\%) patients were discharged after their EDDs; 60 of these patients had an extra unit referral made. Changes in the system for dealing with delayed referrals may decrease delays and may reflect a decreased time in hospital.

This study highlights some of the causes for discrepancies and some areas where system changes may influence the patient's length of hospital stay. That early recognition for patients aged greater than 60 years or with emergency admission status decreases the predictability of the discharge date should be highlighted.

\section{Acknowledgments}

The authors are grateful to staff of the Clinical Effectiveness Department, NHS Grampian, and consultant surgeons, nursing staff, and ward manager of wards 33 and 34 of the Department of Surgery, Aberdeen Royal Infirmary, Aberdeen. 


\section{Disclosure}

A poster based on this work was presented at the 2008 SARS Birmingham and at the International Forum on Quality and Safety in Health Care 2009. The authors report no conflicts of interest in this work.

\section{References}

1. National Workforce Planning Framework 2005: Full Report [webpage on the Internet]. 4.2 Changing the way in which we view the workforce. The Scottish Government; updated 2005. Available from: http://www. scotland.gov.uk/Publications/2005/08/30112522/25285. Accessed April 18, 2011.

2. Department of Health: Public Health, Adult Social Care, and the NHS [homepage on the Internet]. Available from: http://www.dh.gov.uk. Accessed April 18, 2011.
3. A Guide to Service Improvement: Measurement Analysis Techniques and Solutions -Tools and Techniques for the Delivery of Modern Health Care. Edinburgh: Scottish Executive; 2005. Available from: http://www.scotland. gov.uk/Resource/Doc/76169/0019037.pdf. Accessed April 18, 2011.

4. A National Framework for Service Change in the NHS in Scotland: Building a Health Service Fit for the Future. Vol 2. A guide for the NHS. Edinburgh: Scottish Executive; 2005. Available from: http://www.scotland.gov.uk/Resource/Doc/924/0012112.pdf. Accessed April 18, 2011.

5. Delivering for Health [webpage on the Internet]. The Scottish Government; updated 2005. Available from: http://www.scotland.gov.uk/Publications/2005/11/02102635/26365. Accessed April 18, 2011.
Clinical Audit

\section{Publish your work in this journal}

Clinical Audit is an international, peer-reviewed, open access journal focusing on the processes and outcomes of clinical audit in any area of healthcare. All aspects of patient care are addressed within the journal and practitioners from all disciplines are invited to submit their work. Areas covered include: Publication of audits; How an audit has changed practice;

Submit your manuscript here: http://www.dovepress.com/clinical-audit-journal

\section{Dovepress}

Practical tips on how to do audits and to avoid pitfalls; How audits have changed patient care; Calls and justifications for new audits. The manuscript management system is completely online and includes a very quick and fair peer-review system, which is all easy to use. Visit http://www.dovepress. com/testimonials.php to read real quotes from published authors. 